Volume $7 \quad 1994$
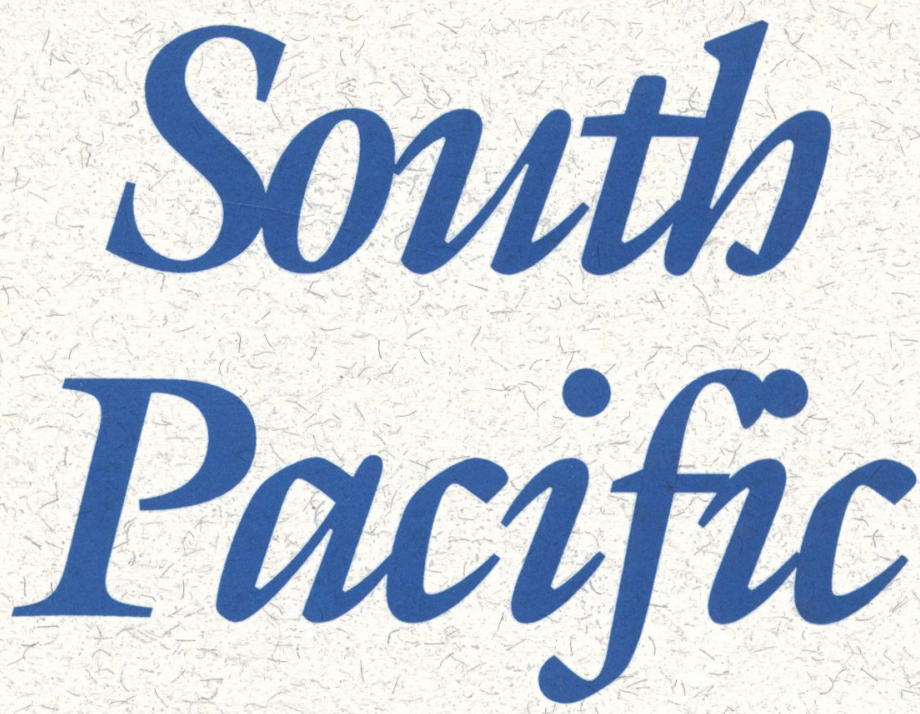

\title{
Journal of Psychology
}

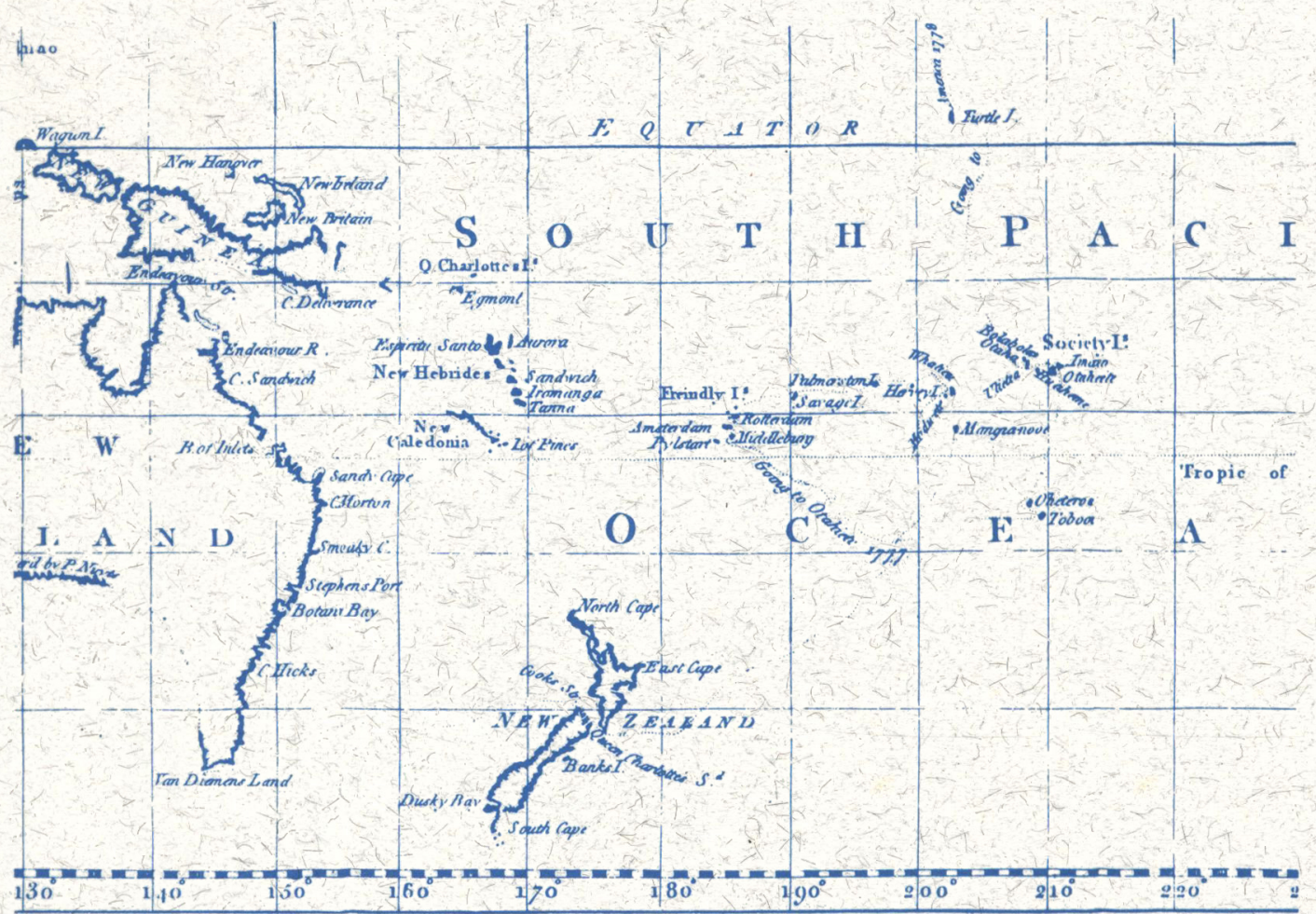




\title{
SOUTH PACIFIC
}

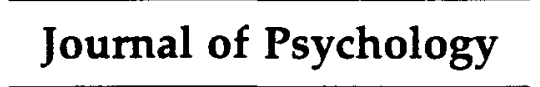

VOLUME 7

\author{
1994 \\ Editor \\ Murray J. Dyck \\ University of Central Queensland \\ Associate Editors \\ Graham R. Davidson \\ University of Central Queensland \\ David Lea \\ University of Papua New Guinea \\ Don Munro \\ University of Newcastle \\ Ross St George \\ Massey University \\ Ron Taft \\ Melbourne \\ David R. Thomas \\ University of Waikato
}

\section{TABLE OF CONTENTS}

EDITORIAL

1

\section{ARTICLES}

Understanding cross-cultural communication

David R. Thomas

Cognitive-behaviour therapy for panic disorder: A Papua New Guinea case

9

Leo Marai

Job satisfaction and burnout among nurses in a metropolitan hospital in

Papua New Guinea

Terence Kuaru

Metacognition, cognition and learning: Old dubitations and new directions

Graham R. Davidson

Personality and dietary correlates of coronary heart disease among Indians

S. Khanna, O. P. Sharma, and B. L. Kotia

See inside back cover for publication policy, instructions to authors, and information concerning subscriptions. 